\title{
Mössbauer studies of Soltmany and Shisr 176 meteorites - comparison with other ordinary chondrites
}

\author{
J. Gałązka-Friedman • K. Szlachta • Ł. Karwowski • \\ M. Woźniak
}

Published online: 10 January 2014

(C) Springer Science+Business Media Dordrecht 2014

\begin{abstract}
Two ordinary chondrites type L6: Soltmany and Shisr 176, were recently investigated in our laboratory. The distribution of iron in the 4 main iron bearing mineral phases (olivine, pyroxene, kamacite and troilite) determined by Mössbauer spectroscopy in Soltmany and Shisr 176 meteorites was very different from that in the Baszkowka meteorite (type L5). To explain the cause of this difference, a comparison of the distribution of iron among the main mineral phases present in other type $\mathrm{L}$ and $\mathrm{H}$ meteorites was performed. Our studies have shown that the Baszkowka meteorite is not a good point of reference for Soltmany and Shisr 176 meteorites.
\end{abstract}

Keywords Ordinary chondrites $\cdot$ Classification of meteorites $\cdot$ Soltmany meteorite $\cdot$ Shisr 176 meteorite

\section{Introduction}

Iron plays a very important role in the evolution of the Universe. Mössbauer spectroscopy was often used to investigate various types of meteorites [1-6].

In general there are 3 groups of meteorites: stony meteorites ( $92.8 \%$ of observed falls) iron meteorites (5.7\% of observed falls) and stony-iron meteorites ( $1.5 \%$ of observed falls).

Stony meteorites are divided into 2 groups: chondrites and achondrites.

Proceedings of the 32nd International Conference on the Applications of the Mössbauer Effect (ICAME 2013) held in Opatija, Croatia, 1-6 September 2013

J. Gałązka-Friedman $(\bowtie) \cdot$ K. Szlachta

Faculty of Physics, Warsaw University of Technology, ul. Koszykowa 75, 00-662 Warsaw, Poland

e-mail: jgfrie@if.pw.edu.pl

Ł. Karwowski

Faculty of Earth Sciences, University of Silesia, Sosnowiec, Poland

M. Woźniak

Faculty of Biology, University of Warsaw, Warsaw, Poland 
Chondrites are characterized by inclusions of chondrules. These are spherical, hard pieces of material, which are mostly of about $2-3 \mathrm{~mm}$ in diameter, but sometimes can reach even $1 \mathrm{~cm}$. The chondrules seem to have once been droplets of molten material that solidified rapidly. In some of the meteorites up to $75 \%$ of the matter is in the form of chondrules. Chondrules are not observed in achondrites.

Ordinary chondrites are divided into 3 types according to their iron concentrations: type $\mathrm{H}$ (with a high amount of iron and a high amount of other metal elements), type L (with a low amount of iron) and type LL (with a very low amount of iron and a low amount of other metal elements). The numbers after H, L and LL (e.g. H6, L5) design the petrologic type of meteorite [7].

In ordinary chondrites, 4 main iron-bearing minerals can be identified: kamacite (Fe-Ni), troilite $(\mathrm{FeS})$, olivine $\left.\left((\mathrm{Fe}, \mathrm{Mg})_{2} \mathrm{SiO}_{4}\right)\right)$ and pyroxene $\left.\left((\mathrm{Fe}, \mathrm{Mg}) \mathrm{SiO}_{3}\right)\right)$. Kamacite and troilite can crystallize only in cosmic conditions, whereas olivine and pyroxene can crystallize also on earth.

The distributions of iron among these four main mineral phases in two meteorites, Soltmany and Shisr 176, were recently investigated in our laboratory $[8,9]$ and were found to be very different from these distributions in the Baszkowka meteorite studied previously [3].

The goal of our studies was to answer the question if these two ordinary chondrites type L6 (Soltmany and Shisr 176 ) are really different from other ordinary chondrites. For this purpose the new classification of meteorites, suggested by Verma et al. [5] and based on Mössbauer spectroscopy, was applied.

In 2003 Verma et al. [5] suggested that Mössbauer spectroscopy can be a very useful technique for the classification of meteorites. They constructed a plot of the absorption areas obtained in Mössbauer spectra for pyroxene against the absorption areas obtained for olivine in 24 ordinary chondrites type H, L and LL. On this plot they were able to observe two separated regions: one for $\mathrm{H}$ and the other for $\mathrm{L}$ and LL meteorites. With this method the authors were able to identify the newly fallen Jodhpur meteorite as LL chondrite.

\section{Material and method}

In this paper the analysis of Mössbauer measurements of 19 ordinary chondrites type L and type $\mathrm{H}$ is presented. Because weathering processes can change the distribution of iron significantly, only meteorites with a low level of weathering (amount of $\mathrm{Fe} 3+$ less than $6 \%$ ) were taken into account. Ten meteorites were measured in our laboratory. Results of nine other meteorites were taken from the literature [6, 10-13].

In our laboratory Mössbauer spectra of ${ }^{57} \mathrm{Fe}$ were measured at room temperature with a conventional Mössbauer spectrometer. A $15 \mathrm{mCi}{ }^{57} \mathrm{Co}$-in-Rhodium source, giving a narrow, unsplit emission line, was used. The $14.4 \mathrm{keV}$ gamma rays were detected by a proportional counter. The velocity scales were calibrated using an iron foil absorber at room temperature. The fitting procedure was performed using the "Full Static Hamiltonian" analysis in the 'Recoil' program. 

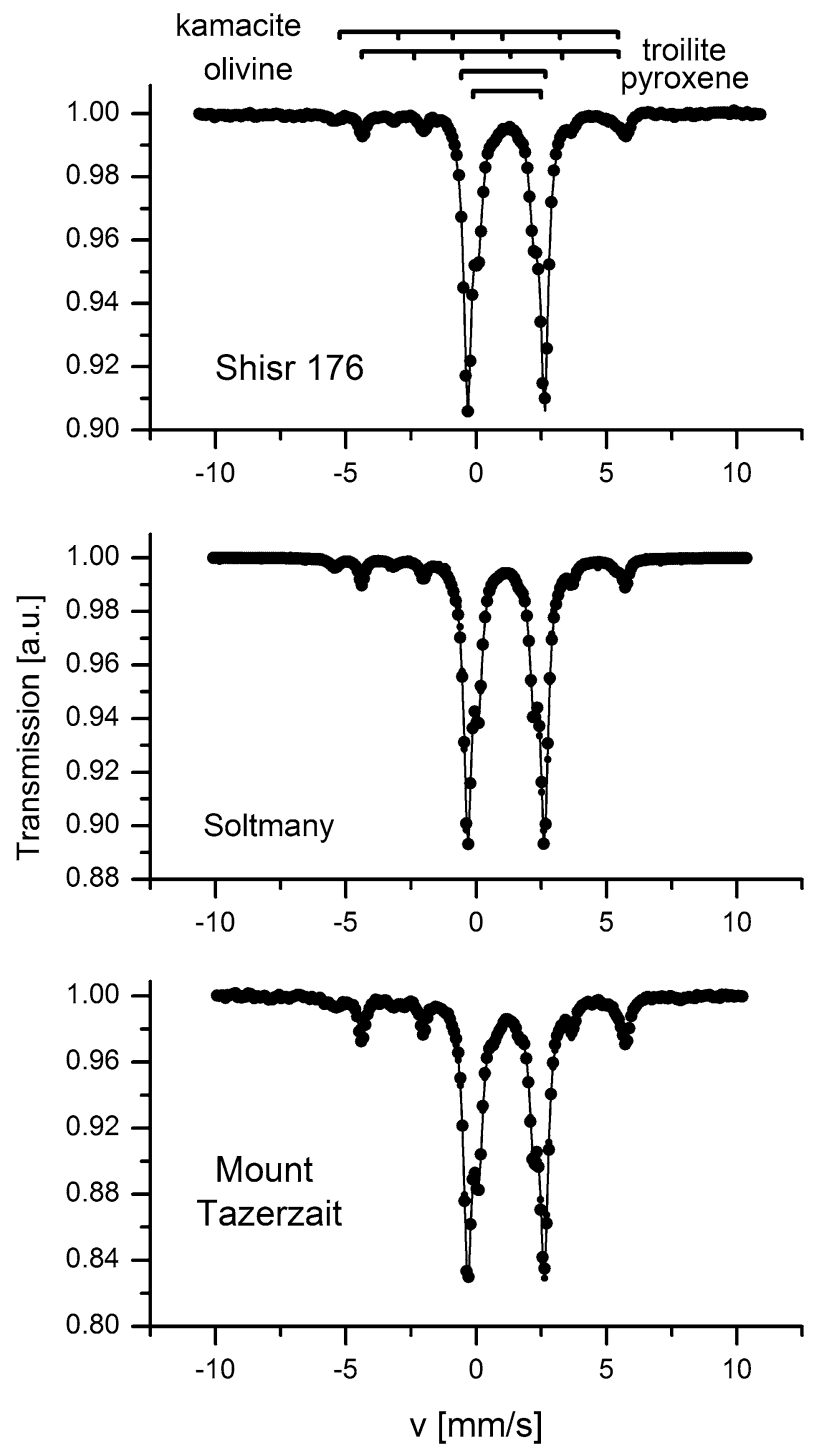

Fig. 1 Mössbauer spectra of meteorites Shisr 176, Soltmany and Mount Tazerzait obtained at room temperature

\section{Description of Soltmany and Shisr 176 meteorites}

\subsection{Sołtmany, an ordinary chondrite L6}

At 6:03 CEST, April 30th, 2011, a stone penetrated the edge of a roof and fell on a concrete step at a farm in the Sołtmany village in Poland. It was immediately found by the owners of the farm, alarmed by the loud noise. On May 2nd, fragments of the stone were purchased and distributed among laboratories for examination. 
Table 1 Mössbauer parameters obtained from the best fit to the experimental spectra. IS isomer shift, $H$ internal magnetic field, $e^{2} q Q / 2$ quadrupole interaction parameter, $w$ HWHM (half width at half maximum), $\theta$ angle between direction of magnetic field and the main axis of the electric field gradient, $A$ relative Mössbauer sub-spectral area

\begin{tabular}{llllllll}
\hline Mineral phase & Meteorite & IS [mm/s] & $\mathrm{H}[\mathrm{T}]$ & $\mathrm{e}^{2} \mathrm{qQ} / 2[\mathrm{~mm} / \mathrm{s}]$ & $\Theta[\mathrm{deg}]$ & $\mathrm{w}[\mathrm{mm} / \mathrm{s}]$ & $\mathrm{A}[\%]$ \\
\hline Olivine & Soltmany & $1.14(2)$ & - & $2.94(2)$ & - & $0.17(2)$ & 59.5 \\
& Shisr 176 & $1.14(2)$ & - & $2.95(2)$ & - & $0.17(2)$ & 64.7 \\
\multirow{2}{*}{ Pyroxene } & Mount Tazerzait & $1.14(2)$ & - & $2.94(2)$ & - & $0.18(2)$ & 49.4 \\
& Soltmany & $1.15(2)$ & - & $2.11(2)$ & - & $0.17(2)$ & 26.0 \\
& Shisr 176 & $1.15(2)$ & - & $2.12(2)$ & - & $0.18(2)$ & 22.3 \\
\multirow{5}{*}{ Kamacite } & Mount Tazerzait & $1.15(2)$ & - & $2.08(2)$ & - & $0.19(2)$ & 25.2 \\
& Soltmany & 0 & $33.5(5)$ & 0 & - & $0.22(2)$ & 4.5 \\
\multirow{2}{*}{ Troilite } & Shisr 176 & 0 & $33.7(5)$ & 0 & - & $0.33(5)$ & 4.0 \\
& Mount Tazerzait & 0 & $33.6(5)$ & 0 & - & $0.36(4)$ & 6.9 \\
& Soltmany & $0.75(2)$ & $30.9(5)$ & $1.00(2)$ & $62(1)$ & $0.14(2)$ & 10.0 \\
\multirow{2}{*}{ Fe3+ } & Shisr 176 & $0.76(2)$ & $31.0(5)$ & $0.75(5)$ & $64(2)$ & $0.15(2)$ & 7.4 \\
& Mount Tazerzait & $0.76(2)$ & $30.9(5)$ & $0.95(2)$ & $62(1)$ & $0.15(2)$ & 14.7 \\
& Soltmany & - & - & - & - & - & n.d. \\
& Shisr 176 & $0.45(3)$ & - & $0.60(5)$ & - & $0.14(2)$ & 1.5 \\
& Mount Tazerzait & $0.37(2)$ & - & $0.73(2)$ & - & $0.28(2)$ & 3.8 \\
\hline
\end{tabular}

The experimental error of A values is about $1 \%$

Table 2 The distribution of iron atoms in mineral phases in 11 ordinary chondrites type L5 and L6

\begin{tabular}{llllcll}
\hline Meteorite & Type & Olivine & Pyroxene & Metallic & Troilite & Ol Ar/Pyr Ar \\
\hline Shisr 176 & L6 & 65.1 & 23.2 & 2.9 & 7.9 & 2.81 \\
Soltmany & L6 & 59.5 & 26 & 4.5 & 10 & 2.89 \\
Kunashak [6] & L6 & 59.8 & 19.2 & 9.1 & 10.6 & 3.11 \\
Mount Tazerzait & L5 & 49.4 & 25.2 & 6.9 & 14.7 & 1.96 \\
Farmington & L5 & 45.6 & 21.3 & 12.6 & 15 & 2.14 \\
Mbale & L5/6 & 39.4 & 19 & 22.7 & 15.2 & 2.07 \\
Barwell & L5 & 48.2 & 24.9 & 6.5 & 15.2 & 1.94 \\
Ohuma & L5 & 47.7 & 23.4 & 6.4 & 19 & 2.04 \\
Al Kidirate [11] & L6 & 46.7 & 23.3 & 11 & 18.9 & 2.00 \\
Colby & L6 & 46.4 & 21.9 & 5.4 & 22.4 & 2.12 \\
Baszkowka & L5 & 30.3 & 19.8 & 19.6 & 28.5 & 1.53 \\
\hline
\end{tabular}

The total mass of the meteorite was estimated to be at least $1066 \mathrm{~g}$. Most pieces had a $1-1.5 \mathrm{~mm}$ thick fusion crust. The crust was of the same thickness all around the meteorite, which confirmed that the stone was a single fall. The hole in the roof and the trace of impact on the step below showed that the fall was nearly vertical. The interior of the meteorite was nearly white, with clearly visible troilite and FeNi grains (up to a size of $3 \mathrm{~mm}$ ), which were dispersed uniformly throughout the meteorite. Only a few chondrules were visible. Chondrule and matrix olivines and pyroxenes showed homogeneous compositions. Opaque 


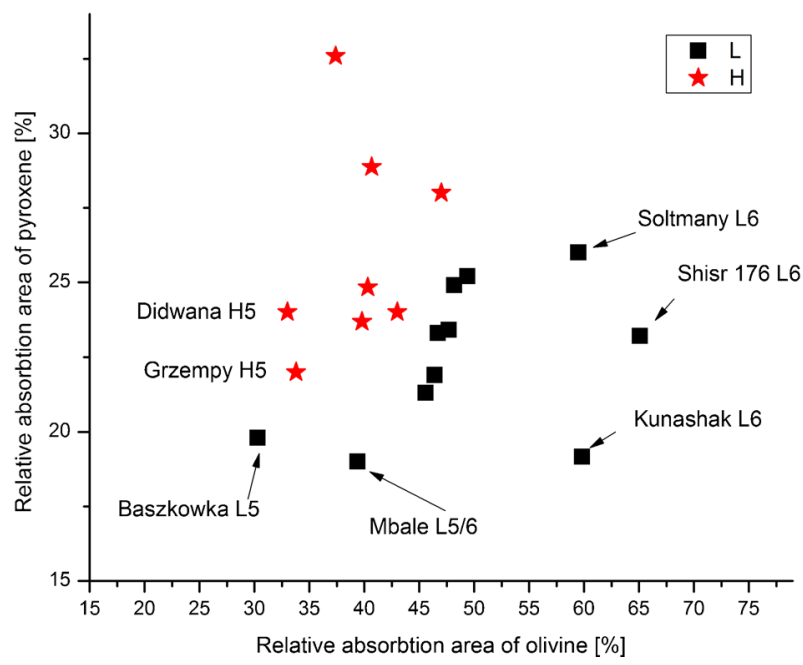

Fig. 2 Plot of relative absorption area of pyroxene vs. relative absorption area of olivine

Table 3 The distribution of iron atoms in mineral phases in 8 ordinary chondrites type H4, H5 and H6

\begin{tabular}{lllllll}
\hline Meteorite & Type & Olivine & Pyroxene & Metallic & Troilite & Ol Ar/Pyr Ar \\
\hline Xinyang [12] & H6 & 43 & 24 & 15 & 16 & 1.79 \\
Ochansk [6] & H4 & 40.7 & 28.9 & 10.7 & 17.4 & 1.41 \\
Vengerovo [6] & H5 & 40.3 & 24.8 & 14.8 & 15.1 & 1.63 \\
Zonkov [6] & H6 & 39.8 & 23.7 & 17.6 & 15.8 & 1.68 \\
Richardton [6] & H5 & 37.4 & 32.6 & 11 & 14.7 & 1.15 \\
Grzempy & H5 & 33.8 & 22 & 31.1 & 11.8 & 1.54 \\
Didwana [13] & H5 & 33 & 24 & 19 & 23 & 1.38 \\
Torino [10] & H6 & 47 & 28 & 9 & 16 & 1.68 \\
\hline
\end{tabular}

minerals were represented by troilite, kamacite, taenite, and rarely chromite. Small grains of copper were visible in taenite grains.

Shisr 176, an ordinary chondrite L6. Eleven, fresh, complete meteorites were found by a Polish team near Shisr, Oman.

Stones were covered mostly by a black fusion crust. Olivine in chondrules and small olivine grains outside of chondrules had similar, low fayalite $\left(\mathrm{Fe}_{2}^{2+} \mathrm{SO}_{4}\right)$ compositions. Chondrules diameters were up to $2 \mathrm{~mm}$. Opaque minerals were represented by troilite, kamacite, taenite, and chromite. Tetratenite occured as separate grains. Small copper grains were found in taenite, kamacite and troilite.

\section{Results and discussion}

In Fig. 1 Mössbauer spectra of three ordinary chondrites type L (Shisr 176, Soltmany and Mount Tazerzait) are shown. In all these spectra, subspectra of iron present in olivine, pyroxene, kamacite and troilite were identified. In meteorites Shisr 176 and Mount Tazerzait the 
Table 4 Comparison of the distribution of iron in mineral phases obtained in different laboratories for 4 ordinary chondrites type $\mathrm{L}$

\begin{tabular}{|c|c|c|c|c|c|}
\hline Meteorite & Laboratory & Olivine & Pyroxene & Metallic & Troilite \\
\hline \multirow[t]{2}{*}{ Farmington } & Warsaw & 45.6 & 21.3 & 12.6 & 15 \\
\hline & Ekaterinburg [6] & 43.4 & 24.3 & 15.2 & 14.8 \\
\hline \multirow[t]{2}{*}{ Mount Tazerzait } & Warsaw & 49.4 & 25.2 & 6.9 & 14.7 \\
\hline & Ekaterinburg [6] & 50.0 & 27.0 & 5.9 & 13.1 \\
\hline \multirow[t]{2}{*}{ Barwell } & Warsaw & 48.2 & 24.9 & 6.5 & 15.2 \\
\hline & Kanpur [5] & 58.0 & 27.0 & 3.0 & 12.0 \\
\hline \multirow[t]{3}{*}{ Mbale } & Warsaw & 39.4 & 19.0 & 22.7 & 15.2 \\
\hline & Ekaterinburg [6] & 52.0 & 23.0 & 6.4 & 14.8 \\
\hline & Kanpur [5] & 53.0 & 23.0 & 0 & 18.0 \\
\hline
\end{tabular}

Table 5 The distribution of iron atoms in mineral phases in 4 different samples of Baszkowka meteorite

\begin{tabular}{lccccr}
\hline Subspectrum & B1 & B2 & B3 & B4 & B $_{\text {mean }}$ \\
\hline Olivine & 33 & 35 & 28 & 26 & $30.3 \pm 2.1$ \\
Pyroxene & 16 & 21 & 24 & 18 & $19.8 \pm 1.7$ \\
Kamacite & 23 & 14 & 13 & 29 & $19.6 \pm 3.8$ \\
Troilite & 25 & 28 & 26 & 1 & $28.5 \pm 1.7$ \\
Fe3+ & 3 & 2 & & & $2.0 \pm 0.4$ \\
\hline
\end{tabular}

subspectrum of $\mathrm{Fe} 3+$ was also detected. Mössbauer parameters obtained from the best fit to the experimental points are given in Table 1. Mössbauer parameters for olivine, pyroxene and kamacite present in the meteorites mentioned above, are the same within the limits of errors. In troilite there are differences in quadrupole interactions (range: $1,00-0.75 \mathrm{~mm} / \mathrm{s}$ ). For the subspectrum of Fe3+ values of IS and QS are also a bit different.

The distribution of iron in the 4 main mineralogical phases is different in each of the investigated meteorites. As we compare the same mineral phase in every meteorite it is not necessary to take into consideration the differences in f-Lamb Mössbauer factor.

In Table 2 the distribution of iron in identified mineralogical phases for ordinary chondrites type $\mathrm{L}$ is given. The distribution for ordinary chondrites type $\mathrm{H}$ is given in Table 3 . The subspectrum with a magnetic hyperfine field of about $33 \mathrm{~T}$ usually contains not only kamacite, but also taenite and tetrataenite. This magnetic phase, according to the nomenclature suggested by Verma et al., was called "metallic".

Figure 2 shows the percentage of iron in pyroxene vs. the percentage of iron in olivine obtained in different meteorites. The points for ordinary chondrites type L are marked by black squares and points for ordinary chondrites type $\mathrm{H}$ are marked by red stars. In this figure three separated regions can be observed: I - region of 3 ordinary chondrites type L6 (Soltmany, Shisr 176 and Kunashak), II - region of ordinary chondrites type L6 and L5 and III - area of ordinary chondrites type H5 and H6. The points representing meteorite Baszkowka and meteorite Mbale are outside areas I, II and III. The simplest explanation for this could be that the analyzed samples were not representatives for the whole meteorite. To solve this problem we compared Mössbauer results obtained for different samples of the same meteorite in different laboratories. The results of this comparison are given in 


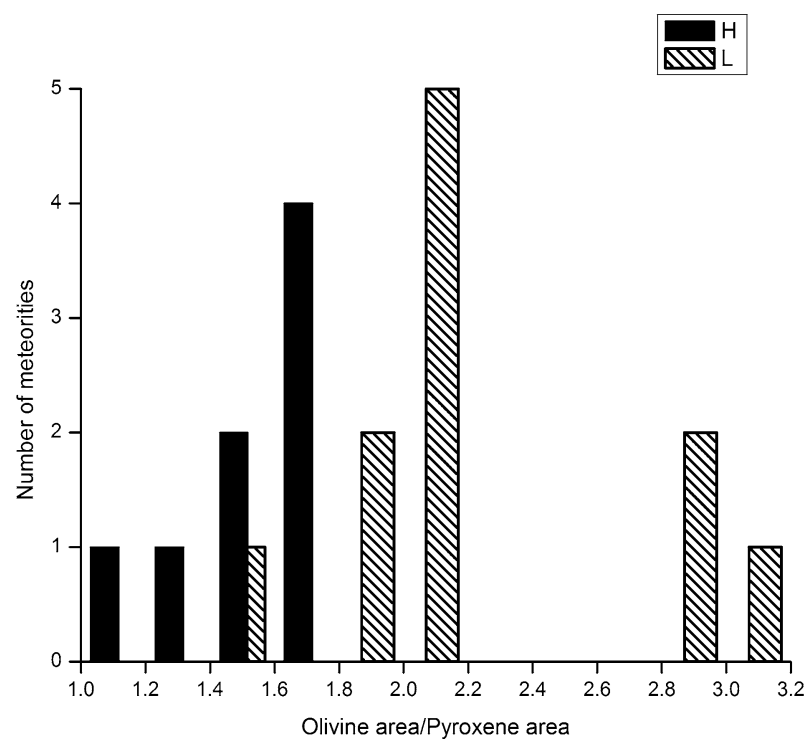

Fig. 3 The ratios of the amount of iron in olivine vs. the amount of iron in pyroxene obtained from the areas of the Mössbauer subspectra for chondrites type $\mathrm{L}$ and type $\mathrm{H}$

Table 4. The differences in the results obtained for samples of meteorites Farmington and Mount Tazerzait, measured in Warsaw and in Ekaterinburg [6] are small and therefore we can treat these results as representative. The difference between the percentage of iron in olivine in samples of meteorite Barewall measured in Warsaw and in Kanpur [5] is much larger (48.2\% vs $58 \%$ ). The largest differences were obtained for samples of meteorite Mbale measured in Warsaw, Ekaterinburg [6] and Kanpur [5], but after the calculating the mean values from three independent measurements, the point presenting this meteorite will move in Fig. 2 to area II.

We cannot explain in this way the unusual position of the Baszkowka meteorite in Fig. 2. The final results for the Baszkowka meteorite were calculated from measurements of 4 samples taken from different places of the meteorite (Table 5). These results should therefore represent the whole meteorite.

In Fig. 3 the ratios of the amount of iron in olivine vs. the amount of iron in pyroxene, obtained from the areas of the Mössbauer sub-spectra for chondrites type L and type $\mathrm{H}$. are shown. In this figure two separated zones are observed: $\mathrm{H}$ - type ordinary chondrites are in the ratio range $1.0-1.8$ and $\mathrm{L}$ - type ordinary chondrites are in the ratio range 1.8 - 3.2. Again, Baszkówka meteorite does not fit the scheme.

\section{Conclusions}

In a plot of the amount of iron in pyroxene vs. the amount of iron in olivine, obtained for 19 unweathered meteorites type $\mathrm{H}$ and $\mathrm{L}$, we were able to distinguish three separated zones. In the first zone ordinary chondrites type L6 with the highest amount of iron in olivine are located, in the second zone ordinary chondrites type L5 and ordinary chondrites type L6 with the lower amount of iron in olivine are present and in the third area ordinary 
chondrites type $\mathrm{H}$ can be found. This segregation does not support the previous hypothesis that Soltmany and Shisr 176 meteorites are very different from other ordinary chondrites. It seems that they belong to the same group as the Kunashak meteorite.

At the present stage of investigation we are not able to explain the atypical position of the Baszkowka meteorite in Fig. 2. In this figure, Baszkowka is located in zone III, occupied by meteorites type $\mathrm{H}$. A possible explanation could be the erroneous classification of this meteorite or an atypical mechanism of distribution of iron among different mineral phases.

It seems that Mössbauer spectroscopy can be a very useful complementary technique for the classification of meteorites.

\section{References}

1. Knudsen, J.M., Morup, S., Galazka-Friedman, J.: Mössbauer spectroscopy and the iron on Mars. Hyperfine Interact. 57, 2231-2236 (1990)

2. Scorzelli, R.B.: Application of the Mössbauer effect to the study of meteorites - a review. Hyperfine Interact. 66, 249-258 (1991)

3. Gałazka-Friedman, J., Bauminger, E.R., Nowik, I., Bakun-Czubarow, N., Stȩpniewski, M., Siemiątkowski, J.: Comparative Mössbauer studies of the Baszkowka ordinary chondrite and some other meteorites. Geol. Q. 45, 319-326 (2001)

4. Forder, S.D., Bland, P.A., Gałazka-Friedman, J., Urbański, M., Gontarz, Z., Milczarek, M., BakunCzubarow, N.: A Mössbauer study of meteorites - A possible criterion to identify meteorites from the same parent body. Hyperfine Interact (C) 5, 405-408 (2002)

5. Verma, H.C., Jee, K., Tripathi, R.P.: Systematics of Mössbauer absorption areas in ordinary chondrites and applications to a newly fallen meteorite in Jodhpur, India. Meteorit. Planet. Sci. 38, 963-967 (2003)

6. Oshtrakh, M.I., Petrova, E.V., Grokhovsky, V.I., Semionkin, V.A.: A study of ordinary chondrites by Mössbauer spectroscopy with high velocity resolution. Meteorit. Planet. Sci. 43, 941-958 (2008)

7. Van Schmus, W.R., Wood, J.A.: A chemical-petrologic classification for the chondritic meteorites. Geochim. Cosmochim. Acta. 31, 747-765 (1967)

8. Gałazka-Friedman, J., Szlachta, K.: Mössbauer studies of Soltmany meteorites - preliminary results. Meteorites (in press)

9. Gałązka-Friedman, J., Szlachta, K., Woźniak, M.: Mössbauer studies of Shisr 176 meteorite - preliminary results. Acta Soc. Metheoriticae Polonorum. 4, 39-45 (2013)

10. Ortalli, I., Pedrazzi, G.: Study of the Torino meteorite. Hyperfine Interact. 57, 2275-2278 (1990)

11. Gismelseed, A.M., Khangi, F., Ibrahim, A.: Studies on Al Kidirate and Kapoeta meteorites. Hyperfine Interact. 91, 551-555 (1994)

12. Zhang, Y., Stevens, J.G., Li, Y., Li, Z.: Mössbauer study of the Jilin and Xinyang meteorite. Hyperfine Interact. 91, 550 (1994)

13. Verma, H.C., Bijalni, N., Truipathi, A., Tripathi, R.P.: A Mössbauer spectroscopic study of simulated weathering of Didwana ordinary chondrite. Hyperfine Interact. 186, 1023-1027 (2008) 